\title{
Cultura de los Cuidados en el último libro de Manuel Moreno
}

\author{
Culture of Care in the last book by Manuel Moreno
}

Cultura de Cuidado no último livro de Manuel Moreno

\section{ENFERMERÍA CULTURAL: UNA MIRADA ANTROPOLÓGICA DEL CUIDADO. MADRID: GARCETA}

\section{Manuel Moreno Preciado}

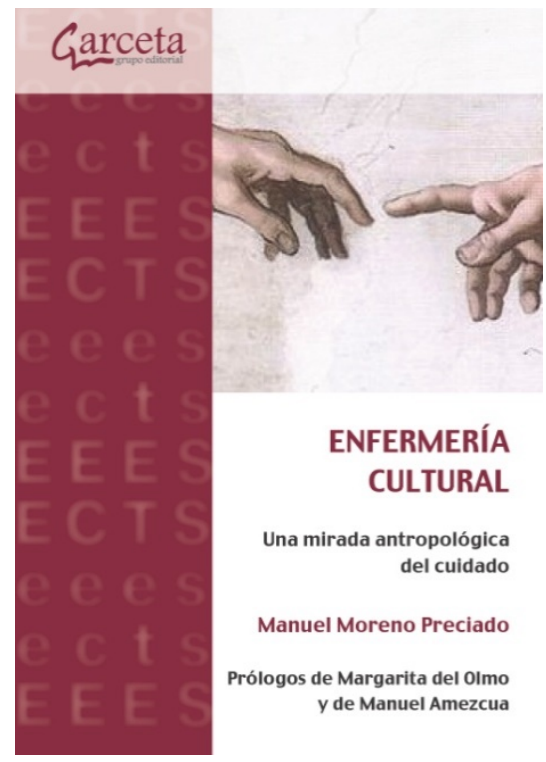

ISBN: 978-84-1728-928-7

Páginas: 397

Carmen Solano Ruíz. Profesora titular. Departamento de enfermería. Universidad de Alicante.

Cómo citar este artículo en edición digital: Solano, C. (2018). Cultura de los Cuidados en el último libro de Manuel Moreno. Cultura de los Cuidados (Edición digital), 22(51). Recuperado de <http://dx.doi.org/10.14198/cuid.2018.51.21>

Correspondencia: Departamento de enfermería. Universidad de Alicante. 03080 Alicante (España). Correo electrónico: Carmen.solano@ua.es 


\section{ABSTRACT}

In this review, we summarize the main features of the last book by Professor Moreno Preciado "Cultural Nursing: an anthropological look of care".

Keywords: Culture of care, anthropology of care, nursing, ethnography.

\section{RESUMEN}

En esta reseña, se resumen las principales características del último libro del profesor Moreno Preciado" Enfermería cultural: una mirada antropológica del cuidado".

Palabras clave: Cultura de los cuidados, antropología de los cuidados, enfermería, etnografía.

\section{RESUMO}

Nesta revisão, resumimos as principais características do último livro do professor Moreno Preciado "Enfermagem Cultural: um olhar antropológico de cuidado". Palavras-chave: Cultura do cuidado, antropologia do cuidado, enfermagem, etnografia.

El profesor Manuel Moreno nos presenta un libro muy interesante fruto de la fusión existente entre las disciplinas de enfermería y la antropología. La labor asistencial desarrollada por el profesor así como su formación como antropólogo han favorecido un conocimiento profundo de ambas disciplinas dejando plasmado evidencia de ello a través de las diferentes líneas de este texto. Fuera de nuestras fronteras y sobre los años 60 la Dra Madeleine Leinniger fue pionera en este campo mostrando a través de su modelo de enfermería transcultural el maridaje entre la cultura y los cuidados. Es a partir de este momento y sobre todo en EEUU cuando se evidencia un incremento de la producción en este campo.

El libro del profesor Moreno podemos afirmar que está dirigido a todos los profesionales de la salud sin necesidad de especialidades, ya que el contacto con la diversidad cultural no precisa del hecho de trabajar con población migrante. En definitiva, puede interesar tanto a profesionales como a estudiantes que están inmersos en el día a día con diferentes culturales como son antropólogos, sociólogos...El autor muestra la obra dividida en tres grandes bloques. El primer bloque realiza una breve introspección hacia la antropología social y cultural estableciendo el vínculo entre salud y diversidad cultural, poniendo de relieve en este apartado los principales factores socioculturales que influyen en el cuidado.

Para continuar con un segundo bloque como es ente fundamental del libro, y el autor lo titula como "Padeceres y cuidados. Perspectiva sociocultural” bajo este título podemos intuir que El Dr. Moreno nos muestra un amplio recorrido por los distintos escenarios presentes en la sociedad actual tocando diversas temáticas con el principal nexo de unión de la mirada sociocultural. Temas como la propia adicción a la modernidad de la sociedad, la construcción social del cuerpo, el significado cultural de los alimentos, la salud de la población migrante así como la cultura de la pobreza para finalizar con el capítulo del proceso de la vejez y la muerte institucionalizada. Una diversidad temática desde una mirada diferente que ayudará a los lectores a comprender la visión actual de la sociedad.

Y por último un tercer bloque dedicado a los aspectos fundamentales de la investigación cualitativa en el marco contextual de los cuidados, centrando su atención principalmente en el método etnográfico como técnica especifica del trabajo de campo.

Me gustaría destacar que todos los capítulos contienen un último apartado que invita al lector a consultar las obras de referencia, sobre todo resaltar el capítulo de narrativa en el cuerpo central del libro en el que propone obras clásicas que ilustran la temática que se ha abordado en dicho apartado confiriéndole a este documento un gran carácter de originalidad.

El glosario que aparece al final del libro se puede considerar de un gran valor científico ya que en todo momento ayuda a conocer en profundidad tanto los términos que van apareciendo a lo largo del texto así cómo los autores más relevantes vinculados con la temática de estudio. 